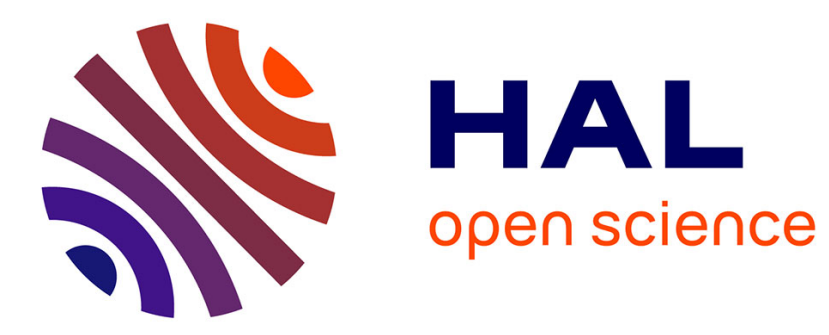

\title{
Increased inhibition of cytochrome P450 3A4 with the tablet formulation of posaconazole
}

\author{
A. Petitcollin, R. Crochette, C. Tron, C. Verdier, C. Boglione-Kerrien, C. \\ Vigneau, E. Bellissant, F. Lemaitre
}

\section{- To cite this version:}

A. Petitcollin, R. Crochette, C. Tron, C. Verdier, C. Boglione-Kerrien, et al.. Increased inhibition of cytochrome P450 3A4 with the tablet formulation of posaconazole. Drug Metabolism and Pharmacokinetics, 2016, 31 (5), pp.389 - 393. 10.1016/j.dmpk.2016.05.001 . hal-01376262

HAL Id: hal-01376262

https://hal-univ-rennes1.archives-ouvertes.fr/hal-01376262

Submitted on 8 Nov 2016

HAL is a multi-disciplinary open access archive for the deposit and dissemination of scientific research documents, whether they are published or not. The documents may come from teaching and research institutions in France or abroad, or from public or private research centers.
L'archive ouverte pluridisciplinaire HAL, est destinée au dépôt et à la diffusion de documents scientifiques de niveau recherche, publiés ou non, émanant des établissements d'enseignement et de recherche français ou étrangers, des laboratoires publics ou privés. 
Increased inhibition of cytochrome P450 3A4 with the tablet formulation

\section{of posaconazole}

Petitcollin A. ${ }^{1,2,3}$, Crochette R. ${ }^{4}$, Tron C. ${ }^{1,2,3}$, Verdier M-C. ${ }^{1,2,3}$, Boglione-Kerrien C. ${ }^{1}$, Vigneau

C. ${ }^{4}$, Bellissant E. ${ }^{1,2,3}$, Lemaitre F. ${ }^{1,2,3}$

Authors' affiliations

1. Rennes University Hospital, Department of Clinical and Biological Pharmacology and

Pharmacovigilance, Pharmacoepidemiology and Drug Information Center, Rennes, France.

2. Rennes 1 University, Faculty of Medicine, Laboratory of Experimental and Clinical

Pharmacology, Rennes, France.

3. Inserm, CIC-P 1414 Clinical Investigation Center, Rennes, France.

4. Rennes University Hospital, Department of Nephrology, Rennes, France.

\section{Corresponding author:}

Antoine Petitcollin

Rennes University Hospital

Department of Clinical and Biological Pharmacology and Pharmacovigilance,

Pharmacoepidemiology and Drug Information Center

2 rue Henri le Guilloux, 35033 Rennes cedex, France

Tel: 0033223234713

Fax: 0033299284184

Email: antoine.petitcollin@chu-rennes.fr 


\section{Abstract}

Being a substrate of the cytochrome P450 3A4 (CYP3A4) isoenzyme, sirolimus metabolism is decreased when posaconazole is administered concomitantly. However, because of the poor bioavailability of the oral suspension of posaconazole with which low plasma concentrations are obtained, CYP3A4 inhibition is weak and a $50-75 \%$ dose reduction of sirolimus is sufficient to avoid sirolimus overdosage. The new tablet formulation allows reaching posaconazole concentrations 3 to 4 fold higher than those obtained with the oral suspension. Based on a case of sirolimus overdosage following posaconazole tablets administration, we modeled the inhibition of sirolimus clearance by posaconazole, and then simulated several dosage regimens of sirolimus taken together with posaconazole tablets. We were able to describe well the interaction, and found a value of IC50 of posaconazole towards sirolimus clearance of $0.68 \mu \mathrm{g} / \mathrm{mL}$. The simulations showed that even a $80 \%$ decrease of the daily dose of sirolimus is unsuitable in many cases with trough concentrations of posaconazole of $2 \mu \mathrm{g} / \mathrm{mL}$. A decrease of $40 \%$ of the dose with spacing administrations of 3 days may be considered. The clinicians and pharmacologists must be warned that the use of posaconazole tablets may result in an inhibition of CYP3A4 of greater magnitude than with the oral suspension.

\section{Keywords}

Sirolimus, posaconazole, drug-drug interaction, pharmacokinetics, cytochrome P-450 CYP3A 


\section{Increased inhibition of cytochrome P450 3A4 with the tablet formulation}

\section{of posaconazole}

\section{Introduction}

Posaconazole is extensively used in transplant patients to prevent and to treat fungal infections. As other antifungal triazole drugs, posaconazole is an inhibitor of the cytochrome P450 (CYP) 3A4 isoenzyme. It was reported to increase sirolimus exposure by 8.9 fold in healthy volunteers and to increase sirolimus concentration/dose ratio by 2.7 fold in hematopoietic stem cell transplant recipients, when administered as a $400 \mathrm{mg}$ oral suspension $\mathrm{BID}^{1,2}$. Therefore, when co-administration cannot be avoided, reductions of 50 to $75 \%$ of the sirolimus dose were proposed at posaconazole initiation with close monitoring of the concentrations and subsequent dosing adaptations $s^{1,3}$.

Pharmacokinetic studies demonstrated a faster achievement of higher concentrations with the new tablet formulation of posaconazole than with the oral suspension ${ }^{4}$. Given that triazole drugs usually inhibit CYP450 isoenzymes in a concentration-dependent manner, drug-drug interaction are expected to be of greater magnitude with posaconazole tablets. However, no interaction study has ever been reported with this new tablet formulation. This issue may however be of utmost importance, as demonstrated by the case we report here. Based on this case, we modeled the alteration of sirolimus clearance following administration of posaconazole. The relevance of current recommendations regarding dose adjustments are discussed and confronted to pharmacokinetic simulations.

\section{Patient and methods}

\section{Case report}


A 23-year-old kidney transplant patient treated with sirolimus $5 \mathrm{mg}$ daily (QD) received the recommended tablets treatment regimen of posaconazole, consisting of a $600 \mathrm{mg}$ loading dose on the first day and then $300 \mathrm{mg} Q \mathrm{D}$, for secondary prevention of invasive fungal infection. Before the introduction of posaconazole, sirolimus trough concentrations ranged between 7 and $10 \mathrm{ng} / \mathrm{mL}$. Given the lack of experience with posaconazole tablets and the low posaconazole trough concentrations obtained with the oral suspension formerly used in our center, only a small increase in sirolimus concentrations was expected a few days after posaconazole introduction because of its extended half-life. However, concentrations monitoring allowed the detection of a severe sirolimus overdosage, with a maximum trough measured at $59.3 \mathrm{ng} / \mathrm{mL}$ on day 4 after posaconazole introduction. Posaconazole trough concentration was measured at $2.82 \mu \mathrm{g} / \mathrm{mL}$ on the same blood sample. Sirolimus was discontinued until achievement of therapeutic trough concentration and was thereafter reintroduced at the dose of $5 \mathrm{mg}$ twice a week, and then reduced to $3 \mathrm{mg}$ twice a week (figure 1). The posaconazole dose was also reduced to $200 \mathrm{mg}$ QD on the $14^{\text {th }}$ day of treatment as trough concentrations remained largely above the recommended target ${ }^{5}$. The patient did not experience any clinically relevant adverse events or biological perturbations following sirolimus overdosage.

\section{Interaction model building}

Blood samples issued from the routine drug monitoring of this patient were used to measure trough concentrations of posaconazole and sirolimus with fully validated LC-MSMS assays ${ }^{6}$. Pharmacokinetic modelling was performed using Monolix 4.3.2. (Lixsoft; Orsay, France). Due to their enhanced bioavailability, the pharmacokinetics of posaconazole tablets was expected to be much different than that of the oral suspension, and because no compartmental model has been published to date with posaconazole tablets, posaconazole 
parameters were estimated directly from the measured concentrations. However, the availability of residual concentrations only and the wide intra-individual variability rendered difficult the estimation. To facilitate the modelling, we performed a graphical extraction of rich pharmacokinetic profiles reported in healthy volunteers and the model was built from these data merged with those of the patient ${ }^{4}$. The influence of the condition (healthy versus patient) was tested as a categorical covariate of the parameters to account for the differences between healthy volunteers and a graft recipient.

Once the parameters of posaconazole were correctly estimated, a full data set consisting of the patient's posaconazole and sirolimus concentrations was built. The pharmacokinetic parameters of posaconazole were fixed to the individual values previously estimated to avoid a biased re-estimation of the parameters due to the implementation of the interaction model. Sirolimus parameters were estimated from a previously published pharmacokinetic model in kidney transplant recipients, with only residual error parameters re-estimation ${ }^{7}$. For both models, log-normal distribution of the parameters was assumed.

The interaction between posaconazole and sirolimus was modelled by applying an inhibition term on sirolimus clearance as follows:

$$
C L_{S I R}=C L \cdot\left(1-\frac{\operatorname{Imax} \cdot C_{P S Z}}{I C 50+C_{P S Z}}\right)
$$

Where $\mathrm{CL}_{S I R}$ is the actual clearance of sirolimus, $\mathrm{CL}$ is the clearance of sirolimus without posaconazole, Imax is the maximum inhibition of sirolimus clearance, IC50 is the concentration of posaconazole that inhibits $50 \%$ of sirolimus clearance, and CPSz is the concentration of posaconazole.

Dosing simulations 
Pharmacokinetic simulations were performed to estimate the pharmacokinetic profiles of sirolimus in the presence of posaconazole with different dosing regimens. For each dosing regimen, 500 individuals were simulated and the $5^{\text {th }}, 25^{\text {th }}, 75^{\text {th }}$ and $95^{\text {th }}$ percentiles were calculated. For the purpose of these simulations, posaconazole parameters were fixed so as to approximately reach the steady state after the two loading doses of the first day, with trough concentrations of $2 \mu \mathrm{g} / \mathrm{mL}$.

\section{Results}

\section{Interaction model}

A one-compartment model with first order absorption and elimination and proportional residual error was implemented to describe posaconazole pharmacokinetics. Sirolimus concentrations were well described using the model published by Lukas and colleagues, which features sequential Erlang absorption and a two-compartment structural model (figure 1$)^{7}$. However, though they used a mixed additive-proportional error model, the proportional error term was poorly estimated with our data and a simple additive residual error model was used instead. Typical and individual values of the parameters are reported in table 1. The value of Imax was fixed to 1 after several runs with systematical convergence to this value. The value of the IC50 of posaconazole against sirolimus clearance was estimated at $0.68 \mu \mathrm{g} / \mathrm{mL}$. All parameters were estimated with good accuracy (table 1 ).

\section{Dosing simulations}

As expected, the maintenance of a dose of $5 \mathrm{mg}$ QD of sirolimus led to overdosage in all simulated patients. The inter-individual variability was very important, with trough concentrations ranging from around $15 \mathrm{ng} / \mathrm{mL}$ at the $5^{\text {th }}$ percentile up to $130 \mathrm{ng} / \mathrm{mL}$ at the $95^{\text {th }}$ percentile. The dosing simulations revealed that with a $50 \%$ dose reduction, there was no significant decrease of the concentrations and almost $90 \%$ of individuals were still above 
the recommended therapeutic range of $4-12 \mathrm{ng} / \mathrm{mL}$ of trough sirolimus. A $80 \%$ decrease from $5 \mathrm{mg}$ QD to $1 \mathrm{mg}$ QD allowed around a third of the simulated patients to reach the therapeutic range, as well as did an adapted regimen of $3 \mathrm{mg}$ every three days. However, these two regimens differed on the values of trough concentrations which were higher with $1 \mathrm{mg} Q \mathrm{D}$, whereas those obtained with $3 \mathrm{mg}$ every three days were close to standard treatment without posaconazole. Similarly, the values of the maximum concentrations were very low with $1 \mathrm{mg}$ QD whereas peak concentrations with $3 \mathrm{mg}$ every three days were close to those obtained with the standard treatment without posaconazole (figure 2).

\section{Discussion}

Based on a case of drug-drug interaction, we established a pharmacokinetic model to describe the inhibition of sirolimus clearance by posaconazole. The concentration-time profile of sirolimus of the patient in absence of posaconazole was comparable to what was previously reported in kidney transplant recipients ${ }^{7}$. Similarly, the trough concentrations of posaconazole where within the range reported in stem cell transplant recipients treated

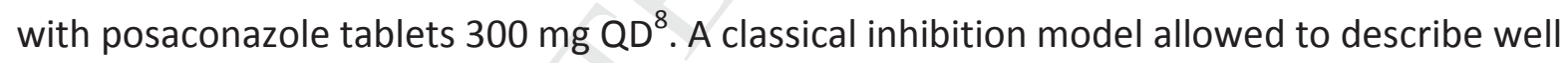
the interaction. The value of the IC50 we estimated was close to that reported in in-vitro studies $(0.91 \mu \mathrm{g} / \mathrm{mL})$, which comforts our results ${ }^{9}$.

The accumulation of sirolimus occurred rapidly after posaconazole was started, sirolimus trough concentration being increased by 5.7 fold after only 2 days of treatment. The concentration/dose ratio was increased by 8.5 fold on day 4 , which is much more than previously reported with the oral suspension ${ }^{1}$. This demonstrates a fast attainment of the concentration threshold for an effective blockade of sirolimus metabolism by CYP3A4 which can be attributed to the use of a loading dose together with enhanced bioavailability of posaconazole tablets as compared with the oral suspension. The pharmacokinetic 
simulations we performed using the interaction model suggested that current

recommendations regarding dose reduction with posaconazole may not be suitable to the use of the new posaconazole tablet formulation, due to this enhanced bioavailability leading to higher concentrations.

As a result of this increased bioavailability, the estimated values of $\mathrm{V} / \mathrm{F}$ and $\mathrm{CL} / \mathrm{F}$ of posaconazole were noticeably lower than those reported before in compartmental studies. However, our data show that despite the improvement of posaconazole bioavailability, an important intra-individual variability remains, which has not been explored to date. This wide intra-individual variability was poorly described by the pharmacokinetic model because only one concentration per week was available, and therefore was not retaind in the final model. However, the concentrations of sirolimus were well predicted using an average concentration-time profile of posaconazole, which indicates that our model describes well the evolution of the clearance of sirolimus. The addition of an inter-occasion variability of the absorption of posaconazole allowed to refine the prediction of its concentrations, but the resulting improvement of sirolimus fitting was modest and thus the simplest model was preferred. In addition, the pharmacokinetic parameters of posaconazole were estimated independently of the interaction model building, and are thus believed to be as strongly estimated as possible with the available data. Moreover, the value of the IC50 was far below the measured trough concentrations of posaconazole, and thus the level of inhibition was close to the maximum over all the observation period. Except made of one concentration, the inhibition level at the time of the trough level ranged between $71 \%$ and $85 \%$. The only low trough concentration of posaconazole, measured at $0.31 \mu \mathrm{g} / \mathrm{mL}$, was largely overestimated which resulted in an underestimation of sirolimus clearance and an overestimation of the predicted concentration of sirolimus (figure 1). 


\section{Conclusion}

Though conclusions cannot be drawn from a single observation, the results of the simulations suggest that current recommendations of dose reduction for the oral suspension of posaconazole might be insufficient with the tablet formulation. If the use of posaconazole cannot be avoided, sirolimus doses should be reduced as soon as posaconazole is started. A $40 \%$ dose reduction administered every 3 days may be suitable. The very high concentrations obtained in certain patients also rises the questions of the reduction of posaconazole doses independently of tolerance issues. A close concentration monitoring is highly recommended from posaconazole initiation to steady-state achievement, and then at least 7 days after posaconazole discontinuation given its extended half-life. Also, given the interaction potential of this new formulation, there is an urgent need to undertake "real-life conditions" studies to explore the sources of pharmacokinetic inter and intra-individual variability of posaconazole administered as tablets. 


\section{Disclosures}

The authors have nothing to disclose.

\section{Aknowledgements}

The authors wish to thank Dr. G. Deslandes for his technical support. 


\section{References}

1. Cho E, Chan H, Nguyen HM, et al. Management of drug interaction between posaconazole and sirolimus in patients who undergo hematopoietic stem cell transplant. Pharmacotherapy. 2015;35(6):578-585. doi: 10.1002/phar.1600.

2. Moton A, Ma L, Krishna G, et al. Effects of oral posaconazole on the pharmacokinetics of sirolimus. Curr Med Res Opin. 2009;25(3):701-707. doi: 10.1185/03007990802644209.

3. Peksa GD, Schultz K, Fung HC. Dosing algorithm for concomitant administration of sirolimus, tacrolimus, and an azole after allogeneic hematopoietic stem cell transplantation. J Oncol Pharm Pract. 2015;21(6):409-415. doi: 10.1177/1078155214539825.

4. Krishna G, Ma L, Martinho M, et al. A new solid oral tablet formulation of posaconazole: a randomized clinical trial to investigate rising single- and multipledose pharmacokinetics and safety in healthy volunteers. J Antimicrob Chemother. 2012;67(11):2725-2730. doi: 10.1093/jac/dks268.

5. ECIL. Accessed april 2016. www.kobe.fr/ecil/telechargements2015/ECIL6-TriazoleTDM-07-12-2015-Lewis-R-et-al.pdf.

6. Verdier MC, Bentue-Ferrer D, Tribut $O$, et al. Liquid chromatography-tandem mass spectrometry method for simultaneous quantification of four triazole antifungal agents in human plasma. Clin Chem Lab Med. 2010;48(10):1515-1522. doi: 10.1515/CCLM.2010.252.

7. Lukas JC, Calvo R, Zografidis A, et al. Simulation of sirolimus exposures and population variability immediately post renal transplantation: importance of the patient's CYP3A5 genotype in tailoring treatment. Biopharm Drug Dispos. 2010;31(23):129-137. doi: 10.1002/bdd.697.

8. Cornely OA, Duarte RF, Haider S, et al. Phase 3 pharmacokinetics and safety study of a posaconazole tablet formulation in patients at risk for invasive fungal disease. $J$ Antimicrob Chemother. 2015;10.1093/jac/dkv380. doi: 10.1093/jac/dkv380.

9. Wexler D, Courtney R, Richards W, et al. Effect of posaconazole on cytochrome P450 enzymes: a randomized, open-label, two-way crossover study. Eur J Pharm Sci. 2004;21(5):645-653. doi: 10.1016/j.ejps.2004.01.005. 


\section{Table}

Table 1. Parameter values in the final model

Sirolimus ${ }^{7}$

$\begin{array}{llll}\text { Parameter } & \text { Estimate } & \text { RSE } & \begin{array}{l}\text { Individ } \\ \text { Estim }\end{array} \\ \begin{array}{l}\text { Fixed effects } \\ \mathrm{k}_{\mathrm{tr}}\left(\mathrm{h}^{-1}\right)\end{array} & 5.26 & \text { fixed } & 5.73 \\ \mathrm{~V} 1(\mathrm{~L}) & 219 & \text { fixed } & 118 \\ \mathrm{CL}\left(\mathrm{L} . \mathrm{h}^{-1}\right) & 15.9 & \text { fixed } & 9.55 \\ \mathrm{~V} 2(\mathrm{~L}) & 273 & \text { fixed } & 404 \\ \mathrm{Q}\left(\mathrm{L}^{-1} \mathrm{~h}^{-1}\right) & 38.2 & \text { fixed } & 38.2\end{array}$

Random effects

BSV on $\mathrm{k}_{\mathrm{tr}}(\%)$

BSV on V1 (\%)

BSV on $\mathrm{CL}(\%)$

BSV on V2 (\%)

BSV on Q (\%)
0.43 fixed $\mathrm{N} / \mathrm{A}$

0.53 fixed $\mathrm{N} / \mathrm{A}$

0.58 fixed $N / A$

0.75 fixed N/A

0.12 fixed $\mathrm{N} / \mathrm{A}$

\section{Posaconazole}

Parameter Estimate RSE $\begin{array}{ll}\text { Individual } \\ \text { Estimate }\end{array}$

\section{Fixed effects}

$\begin{array}{llll}k_{a}\left(h^{-1}\right) & 0.0302 & 4 & 0.0107\end{array}$

$\begin{array}{llll}\beta k_{a} & -1.04 & 23 & \text { N/A }\end{array}$

$\begin{array}{llll}\mathrm{V} 1(\mathrm{~L}) & 14.9 & 14 & 14.9\end{array}$

$\begin{array}{llll}\mathrm{CL}\left(\mathrm{L} . \mathrm{h}^{-1}\right) & 6.91 & 18 & 3.2\end{array}$

IC50 ( $\left.\mu \mathrm{g} \cdot \mathrm{mL}^{-1}\right) \quad 0.681 \quad 1 \quad 0.681$

Imax $\quad 1 \quad$ fixed 1

Random effects

BSV on CL (\%) $0.40 \quad 33 \quad$ N/A

Error model

Proportional

$\begin{array}{llll}\text { error (\%) } & 0.34 & 21 & \text { N/A }\end{array}$

\section{Error model}

Additive error

$\begin{array}{llll}\text { (ng. } \mathrm{mL}^{-1} \text { ) } & 2.03 & 22 & \mathrm{~N} / \mathrm{A}\end{array}$

RSE: Relative Standard Error. BSV: Between Subject Variability. $\beta \mathrm{k}_{\mathrm{a}}$ quantifies the influence of patient condition on $\mathrm{k}_{\mathrm{a}}$. N/A: not applicable. 


\section{Legend to the figures.}

Figure 1: concentration-time profiles of sirolimus (A) and posaconazole (B).

Sirolimus was administered as $5 \mathrm{mg}$ QD and posaconazole as $300 \mathrm{mg}$ twice the first day and then 300 mg QD during 20 days, and then 200 mg QD. After posaconazole was begun, two subsequent doses of sirolimus were given, before temporary discontinuation until the $25^{\text {th }}$ day $\left(600^{\text {th }}\right.$ hour $)$. Sirolimus was then reintroduced at $5 \mathrm{mg}$ twice a week, and then several dose regimens were tested. Finally, $3 \mathrm{mg}$ twice a week was found to best fit to the patient's needs. Full line is the simulated concentration-time profile, points are the measured plasma concentrations.

\section{Figure 2: Dosing simulations.}

A. Sirolimus $5 \mathrm{mg}$ QD. B. Sirolimus $5 \mathrm{mg}$ QD and then $2.5 \mathrm{mg}$ QD from posaconazole beginning (50\% dose reduction). C. Sirolimus $5 \mathrm{mg}$ QD and then $1 \mathrm{mg}$ QD (80\% dose reduction). D. Sirolimus $5 \mathrm{mg}$ QD and then $3 \mathrm{mg}$ (40\% dose reduction) every three days. Posaconazole was begun at the $48^{\text {th }}$ hour, given as one tablet of $300 \mathrm{mg}$ on the $48^{\text {th }}$ and $60^{\text {th }}$ hours, and then $300 \mathrm{mg}$ QD from the $72^{\text {th }}$ hour. Posaconazole parameters were fixed so as to achieve steady state at the third dose $\left(72^{\text {th }}\right.$ hour $)$ with trough concentrations of $2 \mu \mathrm{g} / \mathrm{mL}$. The full line represents the mean simulated sirolimus concentration, dark grey area is from the $25^{\text {th }}$ to the $75^{\text {th }}$ percentile, and light grey areas are from the $5^{\text {th }}$ to the $25^{\text {th }}$ percentile and from the $75^{\text {th }}$ to the $95^{\text {th }}$ percentile. 

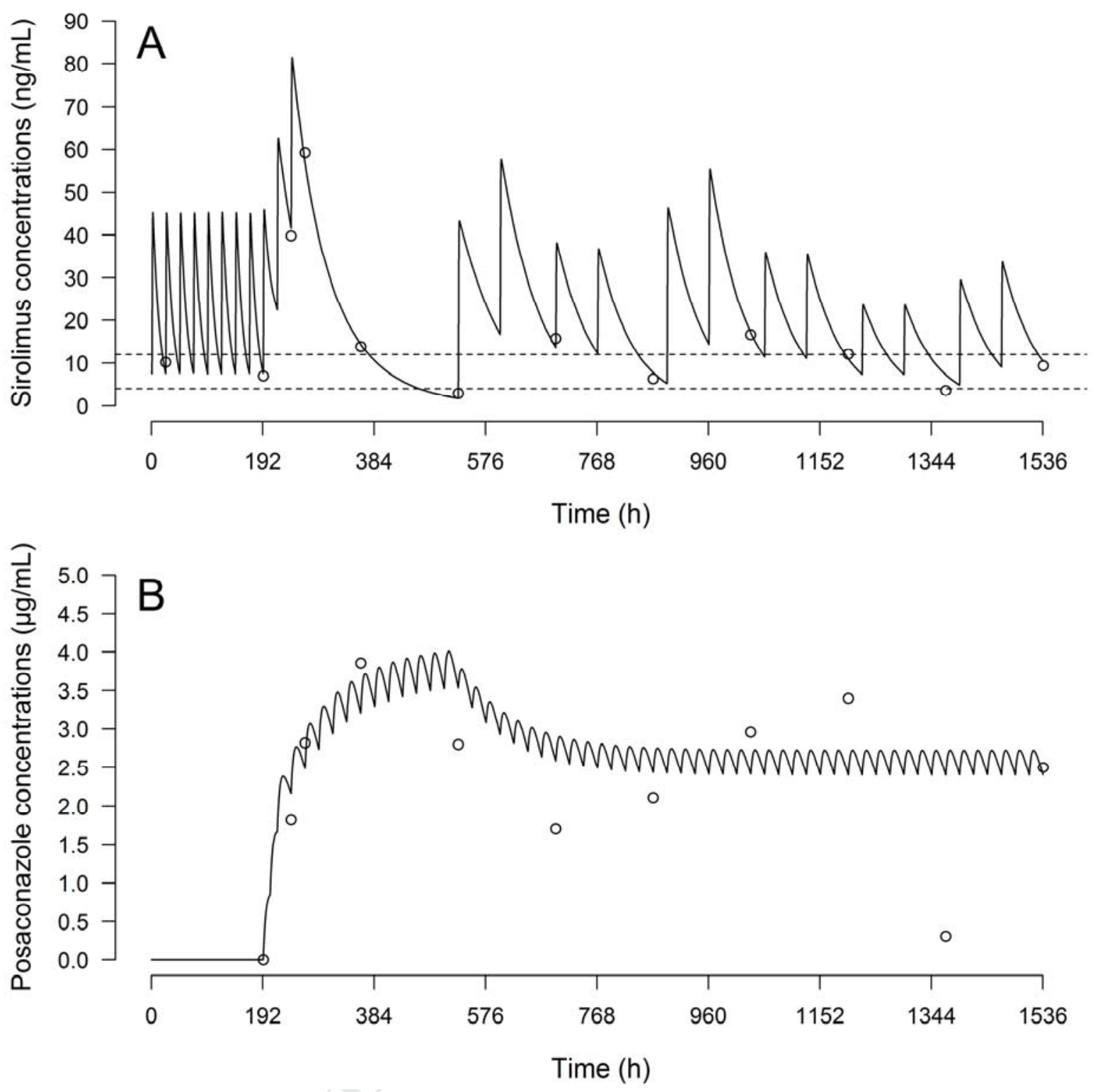

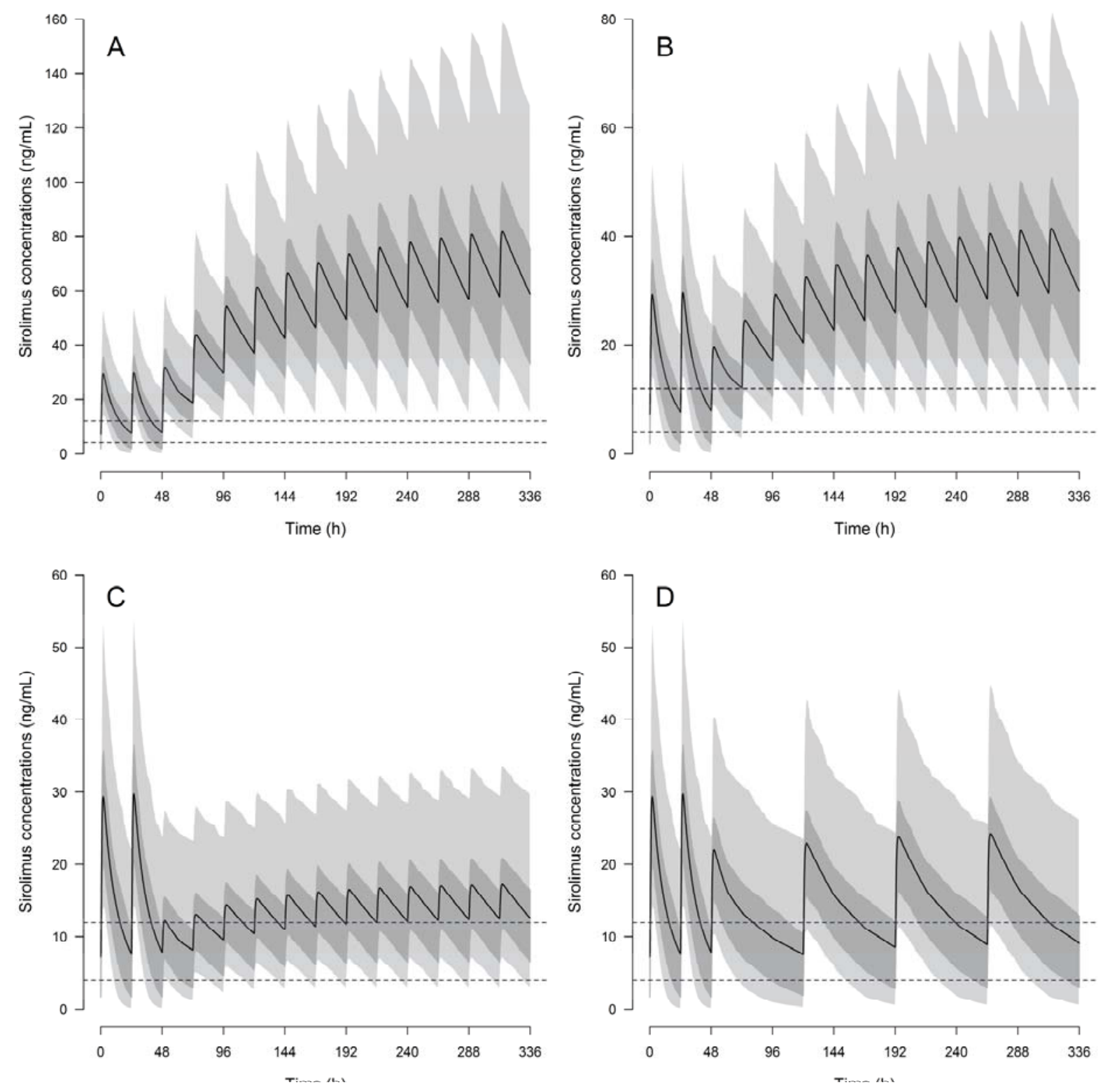